\title{
Sharing Expertise: Easier Said Than Done
}

\author{
Johan Holmqvist ${ }^{1}$, Johan Wenngren ${ }^{1}$, Åsa Ericson ${ }^{1}$, Christian Johansson ${ }^{1}$, Peter Thor ${ }^{1}$ \\ ${ }^{1}$ Division of Functional Product Development, Luleå University of Technology, Sweden
}

\begin{abstract}
An extension towards service provision takes place in manufacturing industry. Inclusion of softer service aspects indicates that the common view on knowledge management to control and monitor a technical process have limitations. Sharing expertise is an additional way of managing knowledge particularly with the intentions to make experience based knowledge organizational available. By studying product developers' daily work, especially how they perceive that they apply and share knowledge, we problematize knowledge activities in product-service development to discuss the established knowledge management activities. The paper suggests some considerations to support the development of a knowledge base for product-service design.
\end{abstract}

Keywords:

Knowledge Management; Knowledge Based Engineering; Web 2.0

\section{INTRODUCTION}

Today, most companies in a business-to-business environment act on a global market. Besides distance and different time zones, such work is also challenged by organizational and cultural differences. In this turmoil, an industrial move towards Product-Service Systems (PSS), i.e. an integration of products and services aspects in early development where the outcome is provided as a function in a service way, is going on. The integration of products (tangible goods) and services (intangible activities) elements is not straightforward due to being based on completely different logics [1]. These challenges make knowledge work and knowledge management an interesting topic from a research perspective, while from an industrial perspective capabilities to handle the situation could be a matter of survival.

There is also a variety of computer based tools that aid technical development. Due to the explicit nature of knowledge the ways of managing technical product related knowledge are well established development activities and processes. So, on one hand, technical product related knowledge could be categorized as explicit since it can be captured and formalized. On the other hand, services are based on experience based knowledge, i.e. tacit knowledge, for example customer perceived value [2], thus such knowledge can as well reside outside the company. Thereby, some vital aspects of experience based knowledge are difficult to pinpoint and to articulate. Commonly, services are described as activities that are co-produced with customers at their time and choosing [3].

Experience based, tacit knowledge is since long ago recognized as an important part of product development [4], though its ambiguousness is evident. For instance, gut feeling or intuition is not a valid decision base, yet they are recognized as affecting decisions. Consequently, this type of knowledge is not made explicit and is not documented to feed input into new projects. The fact that tacit knowledge is not simply identified, captured, formalized or reused contributes to this situation. It can be argued that there are reasons for either ignoring to incorporate such knowledge in the organizational mind, or for failing in doing so. For instance, tacit knowledge cannot be collected in a similar manner as explicit knowledge; hence it needs other methods than those established in traditional product development. Due to its stickiness [5], i.e. it is context dependent [6], it is difficult to transfer into written text. And, it has to be interpreted in a holistic manner. Written text is a common way to capture, for example lessons learned in product development. When tacit knowledge is collected, it usually results in a vast material; consequently it is a tedious work to identify candidate information. Further, due to its contextual dependency, attempts to capture and reuse it risk to detach it from its background. Thus, the good intentions can result in building knowledge silos [7].

Basically, tacit knowledge is embedded in peoples' minds and senses, thus it is not only hard to capture and formalize, but it also follows the employees when they leave the company. When this happens, it takes time for the company to replace what was lost; hence it can cause expensive delays in projects etc.

A way to make experience based knowledge an organizational asset is via socialisation [8], e.g. when people talk about their abstract know-how and share their experiences with colleagues. Stories about how you, partners, colleagues and so forth have dealt with a situation, successfully or detrimentally, support the creation of an organizational culture, but are also a way to share tacit knowledge. However, in technical product development, sharing of experience-based knowledge might not be supported. We have studied technical product developers' work to understand how knowledge is shared. Based on this, the purpose of the paper is to discuss established knowledge management activities to suggest some considerations to support the development of a knowledge base for product-service design.

\section{METHODOLOGY}

The result presented in this paper is built on an empirical study from manufacturing industry. This is an exploratory study from which it is difficult to draw general conclusions. The data is part of a more extensive study, which aims to prescribe methods and tools for 
expertise sharing in technical product development, whereas this paper describes some of the industrial practice. Hence, the paper present a glimpse of an ongoing study performed in two joint industrial/academia research projects. And, the generated data have been used as a part of a pre-study for two research projects.

The two companies, share the same parent company, are active at two different markets, but have a common product development process. Both of the research projects focus knowledge sharing in technical product development, but differ in terms of particular interest in team-based innovation and tools for knowledge sharing. Background material has been generated in company visits and workshops at the companies.

The companies have assisted in finding interesting respondents based on a description of interest areas. A questionnaire has been answered by 7 respondents and 3 interviews have been performed at company $A$. The interviews were performed with engineers from the methods development domain. At company B, 8 respondents have been interviewed. The interviews followed an interview guide with predefined questions. All questions were focusing on the topics knowledge, engineering knowledge and approaches for knowledge sharing. Intentionally, we have not defined knowledge in our questions, rather the respondents were free to base their answers on what they perceive as knowledge. And, all interviews were semistructured, i.e. the respondents could formulate answers freely and the researcher can pose follow up questions on interesting topics.

\section{KNOWLEDGE MANAGEMENT}

Commonly, product development is described as knowledge intensive work. Though, depending on the prevailing perspective, what kind of knowledge it involves differs. Particularly for PSS situations it is concluded that there are differences between an industry and technologist view versus a service research and service perspective point of view [9]. For manufacturing companies, moving towards PSS, there is a challenge in integrating the service aspects in the development process and so far many companies that offer services do not fit these with the existing Product-Service System [10].

A comparison of competing paradigms of product development in academic communities have recognized marketing, organization, engineering design and operations management as main conflicting perspectives [11]. Particularly the view on products differs between the perspectives (p.3). From a marketing perspective the product is "...a bundle of attributes", making customer preferences of those attributes important knowledge. From an organizational perspective the product is considered to be "...an artefact resulting from an organizational process", making knowledge of creating internal workflow vital. Engineering design views the product, first as something discrete and manufactured [12], second as a "...a complex assembly of interacting components" [11], making knowledge about the technical device and its interfaces a priority. Finally, the operations management point of view defines a product as "...a sequence of development and/or production steps", indicating a focus on process knowledge. And, all these divergent views on knowledge insist on different performance metrics decision variables and success factors [11]. Hence, the knowledge management insists being performed differently. Within adjacent areas, earlier studies have been done but from another perspective [13].

Knowledge is commonly described as contemporary organizations most important resources. Though, in product development literature the view on knowledge is typically described from an engineering design perspective. Thereby, formalizing and storing of knowledge for the purpose to reuse it is in focus [14]. The engineering design expertise can be formulated as "rules of thumb" and applied in knowledge based systems applications [14].

Knowledge management can be divided into two main approaches [15][16]. The first focuses on gathering, collecting, storing and reusing knowledge, mainly as a method to control and monitor, for example, a development process [15]. The second focuses on knowledge creation, integration and sharing, mainly applied to bolster human components of knowledge [17]. The second approach is commonly called knowledge sharing or expertise sharing [15], rather than knowledge management. In expertise sharing, the problems of cross-boundary knowledge work and social aspects are recognized [17]. The aim for knowledge sharing is to support communication, learning and organizational knowledge [17], consequently it gives knowledge management the task to transform tacit knowledge into explicit knowledge, as well as transform individual knowledge into organizational knowledge. Commonly, such a transformation is explained to depend on a change in mindset, similar to the change into "Toyotism" or "Just in Time" required a change of mentality rather than a change in "machinery" [18]

\section{PRODUCT-SERVICE SYSTEMS}

In industry, several different terms are used to describe the phenomena of PSS; soft products, total offers, through life solutions, and service 2.0 offerings are some examples.

Tukker et al [19] provide a list of 9 definitions where it can be noticed that the definitions deal with explaining that product-service systems are a mix or a combination of products and services, but give limited explanation of the system part. The system view of PSS seems to address other aspects than an integrated product view does, but this is not further explained.

In a similar way as Krishnan and Ulrich [11] explains a product from different perspectives, PSS could be assumed to be seen from different points of view, but all definitions presented in Tukker et al [19] seem to describe a strategic business point of view where the emphasis is on what is sold to customers, cf. a marketing point of view of what a product is. One example of a definition is that PSS is the result of an innovation strategy, shifting business focus from designing and selling physical products only, to selling a system of products and services which are jointly capable of fulfilling specific client demands [20]. Another example is that PSS are a specific type of value proposition that a business (network) offers to (or coproduces with) its clients [19], this is also based on a marketing/organization business perspective.

Two cornerstones of PSS are outlined to provide guidance for development of solutions [21]:

1. The point of departure for development of PSS should be the functionality or the objective that the user/customer is striving to achieve, rather than to start with a product that fulfills certain functionality.

2. A "green" strategic thinking for the whole business and the company should continuously be modified, instead of taking existing structures and the company's position for granted.

From this guidance, it can, firstly, be interpreted that a development process for PSS always have to start at the customer's place and that no idea of a product to solve that situation should be in mind. Consequently, PSS development has similarities with wicked [22] or ill-defined problems [23], i.e. "...before designers can solve a design problem they need to understand some basics - such as what they are designing, what it should do and who should use it and in what circumstances." [24] (p.2). If so, the product developers' technical knowledge base is not encompassing enough. And, to 
achieve PSS, the company's capabilities of radical, rather than incremental innovation, need to be refined. Second, an interpretation of the guidelines can also be that companies are challenged in a much more extensive way than just figuring out how to mix or combine product and service solutions.

A base for innovations is that some aspects of new knowledge are added to the existing knowledge base [25], such knowledge can be about markets, processes, ideas, products, structures etcetera.

\section{KNOWLEDGE MANAGEMENT IN THE INDUSTRIAL CASES}

The companies in the study are moving towards PSS, but do not have an integrated process for services. Offered services are typically offered as add-on to products. One of the companies has tried PSS on contract level but not on a development level.

For the companies included in this study, knowledge based tools play an important role to validate the included technologies, the manufacturing processes and the use of the product. These tools make storing, retrieving and dissemination of technical information manageable. Also, the tools provide traceability of performed activities, as well as provide the possibility to transfer production and usage information into earlier stages. These tools have to be built on verified knowledge, for example defined governing processes, design practices, method descriptions and standards. In early development, these tools are valuable for simulating and visualizing potential solutions before developing physical prototypes, thus, decreasing both risks and cost.

One of the companies is performing in house development of some knowledge based tools, which is referred to as method development. For a method developer, applications such as the formalization of knowledge into information or expert systems are at the core. But, also, they have to understand how to implement, how to educate users and scalability aspects of the application.

Method development is mainly pursued on a need basis at the company, where for example a project leader identifies an activity that needs improvement or support. The method developer investigates the situation, analyzing the purpose of the task, the steps included, the input information etcetera. Thereby, part of the method developer's work is to identify, justify, capture and formalize knowledge. This work is guided by a knowledge based engineering lifecycle (cf. [14]). The method developer has an extended responsibility to package and activate the application in collaboration with the IT-department. The method developers emphasize that the success of the application depends on how well it fits into the established development process, its usability and if it is accepted by its users. Besides collaboration with IT-department, the method developers work closely with people that are considered as domain experts, such as process owners. These people possess deep and focused knowledge about certain activities and provide valuable input to the method development.

Sometimes the method development follows a technology push approach, where the method developer locates an activity that is not supported (automated) yet, but have the potential of being improved. In such a case, the demands on the developer are different. Usually, the method developer identifies the governing processes and the documented instructions for the activity. Since all activities are not documented and described at the company, the method developers have to solve problems as they emerge. Thus, feeling comfortable with a "learning by doing" approach is part of the task. There is a team of method developers that can seek support among each other. For example, reoccurring meetings, as well as documented guidelines and instructions for method development found in collaborative repositories, such as collaborative workspaces and networked disk drives, are seen as knowledge sharing activities.
The respondents find that knowledge sharing in product development is closely linked to the project and group activities. In this context, verbal communication is a common way to share experiences. Respondents stressed that team members or colleagues commonly ask for guidance or help. Email and chat conversations are mentioned as a way to contact people within the organization, commonly this is done to set up a face to face meeting. Project portals, team portals and chat applications are used for written text, pictures, presentations, CAD models and so forth. These support systems make it possible to form dispersed teams or a dispersed project organization.

Company servers are used to disseminate formal and organizational documents, for instance written instructions, lessons learned, standards, best practice and design practice. The staff can search the servers to find relevant information, though it is expressed that finding information is perceived as time consuming. The engineers prefer to ask a colleague or find a former team member to ask, this is an easier way to retrieve information.

\subsection{How often do you share knowledge?}

The very open-ended question "How often do you share knowledge (within a certain context)?", gave, as expected, different degrees of occurrence. We used follow up questions, like, "with whom?", "why?" and "how?" to gain more detail in the answers.

How often the respondents shared knowledge within the organization was said to depend on their position in the company. For example, those who worked as project leaders perceived that they did share knowledge within the organization; such activities were explained to occur many times a week and concerned mainly project issues, $13 \%$ in Figure 1 . The $12 \%$ of knowledge that was shared on daily basis was explained as reporting progress in projects to other involved or personnel higher in the hierarchy.

$69 \%$ of the respondents perceived that they seldom shared knowledge within the organization, i.e. outside their department and outside their projects. None of the respondents agreed that knowledge sharing occurred constantly (see Figure 1)

\section{How often do you share knowledge? (within the Organization)}

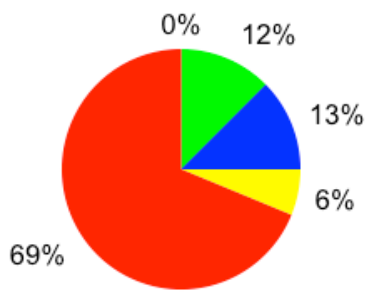

$$
\begin{aligned}
& \text { - Constant } \\
& \text { - Daily } \\
& \text { - Many times/week } \\
& \text { Few times/week } \\
& \text { - Seldom }
\end{aligned}
$$

Figure 1: Knowledge sharing within the organization.

Knowledge sharing with colleagues at a department level visualizes other responses, see Figure 2. 


\section{How often do you share knowledge?}

(within the colleagues)

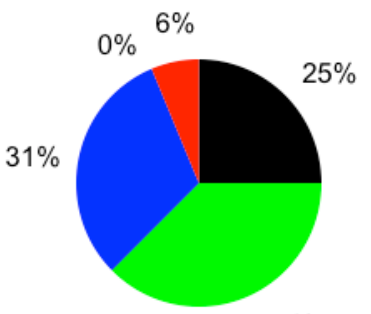

$38 \%$
- Constant

Daily

-Many times/week

Few times/week

- Seldom

Figure 2: Knowledge sharing with colleagues.

In Figure 2, constant (25\%), daily (38\%) and many time/week (31 $\%$ ) indicates that knowledge sharing is perceived as occurring more frequently when viewed in the context of colleagues.

The projects in this study are branded by the company as technical projects. There was a mix of expertise in the team, but that mix was overall from within the engineering field.

In Figure 3, sharing knowledge at the project level is shown. $13 \%$ of the team members perceived that they shared knowledge within the project constantly, $19 \%$ expressed that they did share on a daily basis, and $31 \%$ shared knowledge many times/week. Also, 31 $\%$ perceived that they shared knowledge only a few times/week, and $6 \%$ expressed that they seldom shared knowledge within the project.

\section{How often do you share knowledge?} (within the project)

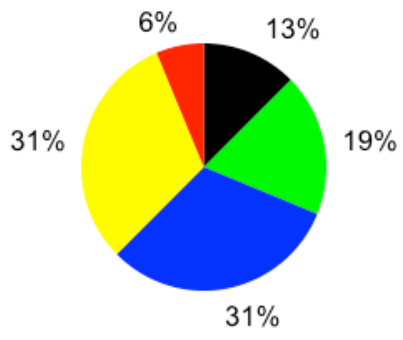

- Constant
Daily
- Many times/week
Few times/week
- Seldom

Figure 3: Knowledge sharing within the project.

\subsection{Where do you find information?}

Knowledge or information reuse is important to maintain effective project work, to support this; the members have access to information systems as for example lessons learned systems, project archives, product assurance plan. Lessons learned systems are used to capture experience based knowledge from the projects, documents related to the project work are stored in the project archive, and the product assurance plan defines the delivery criteria for opening gates in projects according to the product development process.

\section{You need information/knowledge from a previous/closed project, what is the first place you look at?}

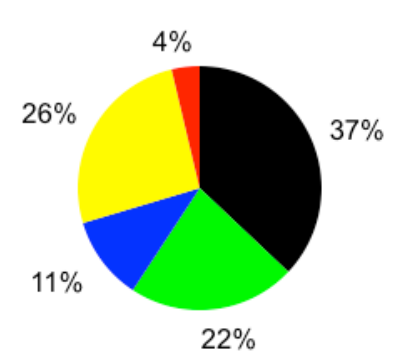

- Colleague

Previous member of the project/Domain experts

- Lessons learned system

Projects archive

- Product assurance plan
Figure 4: Where do you search for information or knowledge.

In Figure 4, $37 \%$ of the respondents answered that they firstly asked a colleague, which is a person from the same department when they are seeking for information from a previous project. $22 \%$ identified a previous project member or domain expert to find information. Only $11 \%$ looked first into lessons learned systems, and $26 \%$ in the project archive.

One reason for information systems applications as not being the first and most natural choice was explained by the respondents as related to the difficulties to search for the information. To be able to search you have to have some idea (words, project name, project members etcetera.) of how the information is tagged and stored, this is found in the case studies and supported by the literature [26].

\section{IMPLICATIONS FROM THE STUDY}

There are a number of implications from the study that needs to be discussed, though a contribution from it is that it provides an overview from which further research activities can embark. For industrial practices, the discerned indications can provide a basis for reflection.

The generation of data did not focus on finding out individual's perceptions of 'what' was shared, i.e. their definitions of knowledge or information. Instead the study is built on the respondents' views of 'if' they share or not, meaning that the respondents were free to interpret what is knowledge and what is information. We have in previous studies found that defining knowledge is not straightforward and those attempts did not provide guidance for how to support the sharing activities. In those previous studies the respondents have been able to, theoretically, define knowledge as something else than information, but when they start to describe their work they apply a more practical definition, i.e. what they need to know to do their work is expressed as knowledge. Within the engineering practice area, the perception is that some of the companies' applications are built upon information (facts, figures, calculations, test results and so forth). And, it is the human and contextual interpretation of that displayed information that transforms it into knowledge. Still, this is found as a theoretical discussion rather than a practical one.

However, in the study presented here there seems to be a difference between that practical view of knowledge and another view of knowledge, which can be categorized as 'experiences'. Thus, making the perception of shared knowledge to align with explicit knowledge and information, and making the distinction that what is not so frequently shared is experiences. If so, the continuation of these research projects could benefit from studying 
experiences, what it is, how it affects project work and how it can be made organizationally available.

The lessons learned systems are tools to capture and disseminate experiences, but as indicated in this study the respondents did not have trust in finding the information needed, i.e. those systems were not their first choice of knowledge source. The study presented here does not provide insights into the reasons, but indicates that the information retrieval from lessons learned systems is perceived as bringing limited benefits in project work. If so, it might be possible to suspect that the information input could be sparse also. Experiences often come in 'eureka moments' [27] from which lessons learned has to be reflected on. Is so, the team have to have the possibility to reflect in practice in the 'eureka moment', rather than after project closure to avoid hindsight and construction of experiences. Yet, how can such activities be supported and performed in practice? And, the support for capturing these reflections in action, how would that look like? Reflections in teams usually do not come in written text, rather in dialogues.

Before the study, it was assumed that knowledge sharing activities should be most frequent within the project and that knowledge sharing should be less frequent on an organizational level. The empirical data indicates that the assumption has some relevancy, but provides no insights to why a situation like this could occur. One explanation could be that the purpose for overall organizational activities is more or less to pass on information from high level management, for example to communicate what is happening in the company as a whole or to transfer information about the business environment. If so, there is a need of an organizational strategy to support other forms of meeting that support knowledge sharing. It seems useful to; for example, figure out how to provide structured and focused feedback from a larger audience and how to evaluate the impact of an informative meeting in order to improve the large meeting format for knowledge sharing. Though, it is important to note that all larger meetings should not turn into knowledge sharing activities, information transfer is also needed. Basically, there is a need to consider how to find dynamic and useful meeting formats for any specific agenda.

\section{DISCUSSING KNOWLEDGE MANAGEMENT}

In general, companies emphasize that their knowledge base are their most valuable asset. A key in this perspective is if the asset is considered to be protected (not shared) or if it is considered to be accessible to evoke, for example, innovations and collaboration. A basic PSS cornerstone is that it should be a strategic and holistic effort in collaboration with partners [21].

Typically, earlier research efforts within the knowledge management field focus on the first approach, i.e. how to store and reuse factual and explicit knowledge [15]. But, as the areas of computer technologies mature and are more capable to deal with automation of knowledge work the interest is turning towards perceived and experience based knowledge. Still, in companies, there is an awareness of the challenges to transform the stored information into actions and the staff into knowledgeable workers.

For manufacturing companies, the extension towards PSS provision seem to change the core of the knowledge base since service experience based knowledge have to be considered in early development. The engineers experiences are seldom shared in formal reports but are a necessity in the development of services, i.e. the experiences is shared verbally and is therefore often missing in activates related to knowledge management work. Donald Rumsfeld, US Secretary of Defense during the first years of 2000s, has received much biting wit from media, but pinpointed important knowledge aspects when he coined the concepts of 'known knowns' (the facts that we know something about), 'known unknowns' (those things we know that we miss information about) and, 'unknown unknowns' (for us unknown information that we do not even realize that we miss). Modica and Rustichini [28] mentioned the concept of 'conscious uncertainty', a state of knowing that we do not know something, as opposed to 'unawareness' that denotes that we do not know something and we do not know that we do not know it.

The analogy of PSS is that manufacturing companies generally can perceive a shift as ill-defined and wicked [22] [23], hence a stepwise extension of business models might be recommended as an approach. Contemporary knowledge based systems, such as knowledge based engineering tools and other repository based knowledge tools are useful for developing physical artifacts, but they do not in their as-is state support PSS as a whole. The ambiguous and uncertain nature of development activities that often goes hand in hand with PSS and service provision means that the knowledge base have to be built upon a 'learning by doing' approach. If this is the case, striving for providing, for example leasing, would build up service knowledge, subsequently how to develop suitable physical products for a leasing contract is one step towards PSS. And, from these experiences how to change the product development process can be understood.

A consideration for PSS is its appropriateness for any kind of products and any type of companies has to be done. PSS, it seems, has become a wider concept than intended, branding all the variants of traditional sales of things (development as usual) to the view that all products remain in the ownership of the manufacturer and that company sell the service of operations in the customer processes [9]. Today, engineers and product developers have to possess a wide range of knowledge, though still that vast knowledge base is about the physical product. PSS adds more relational complexity into that situation, since for development issues the engineers and developers have to expand their knowledge domains into the area of customers.

Knowledge sharing, i.e. second approach of knowledge management [15], need to be built on strategic intentions and allocation of appropriate means. To be made into an organizational knowledge asset, the transformation of information into actionable expertise needs an approach of interpretation, digestion, 'eureka moment' and reflection. These kinds of activities are hard to support in project work. Further, such knowledge sharing occurs more verbally, in sketches, simple pictures and even by using gestures. So, sharing expertise is easier said, than done.

\section{CONCLUDING REMARKS}

This paper outlines results from a study of technical product developers' work performed to describe and understand how knowledge is shared. Besides interaction with company representatives in the research projects, Interviews that composed of predefined questions have been performed. This data provide a background for the purpose of this paper to discuss the established knowledge management activities to suggest some considerations to support the development of a knowledge base for productservice design.

Intentionally, the paper takes a stance to problematize contemporary management of knowledge for the purpose of PSS introduction in the company. Thereby, an interpretation can be that the paper describes a hopeless situation where little can be done. On the contrary, by seeing something as problems, solutions can be found.

The considerations for PSS that we propose need further attention are: 
- The differences between factual knowledge about artifacts and experiences (tacit knowledge) from the team (for example about the thing, its users or its use). How to assure that more aspects than mere technical end up in a knowledge base?

- The multifaceted approach of knowledge sharing, e.g. in dialogues (planned/formal, not planned/informal and so on). How to support different types of meetings?

- The wide range of which knowledge is expressed (text, pictures, drawings, sketches, gestures and so forth). How to provide tools and methods that build on all these aspects?

- The wickedness of the term knowledge and how it is differently applied at distinct levels of the organization. How to create a knowledge sharing culture?

\section{ACKNOWLEDGMENTS}

We would like to acknowledge the ProViking research programme from SSF (Swedish Foundation for Strategic Research), and FFI Strategic Vehicle Research and Innovation (a partnership between the Swedish government and automotive industry) supported by VINNOVA. We would also like to thank the case companies and the respondents of the interviews that this paper is based on.

\section{REFERENCES}

[1] Vargo, S.L., Lusch, R.F. (2004): Evolving to a New Dominant Logic for Marketing. Journal of Marketing. 68: 1-17.

[2] Bovik, C., (2004): Customer-Perceived Value in Business Relationships, Doctoral thesis 2004:44, Division for Business and Economics, Department of Business Administration, Karlstad University, Sweden.

[3] Grönroos, C., (2000): Service Management and Marketing: A Customer Relationship Management Approach, Wiley, Chichester.

[4] Hubka, V., Eder. E., (1996): Design Science: introduction to the needs, scope and organization of engineering design knowledge. Springer Verlag, London.

[5] Ipe, M., (2003): Knowledge Sharing in Organizations: A conceptual framework. Human Resource Development Review, Vol. 2, No. 4, pp. 337-359

[6] Nonaka, I., (1991): The knowledge-creating company, Harvard Business Review, pp. 97-104.

[7] Tomkins, C., (2001): Interdependencies, trust and information in relationships, alliances and networks, Accounting, Organizations and Society, Vol. 26 No. 2, pp. 161-191.

[8] Nonaka, I., Toyama, R., Konno, N., (2000): SECl, Ba and Leadership: a Unified Model of Dynamic Knowledge Creation, Long Range Planning, Vol. 33, No. 1, pp. 5-34.

[9] Fransson, M., (2004): Verkstadsindustrins tjänstefiering - en explorativ resa i det nya affärslandskapet (In Swedish). Licentiatuppsats 2004:24, Institutionen för ekonomi, Centrum för tjänsteforskning, Karlstads Universitet, Sweden.

[10] Fischer, T., Gebauer, H., Gustafsson, A., Witell, L., (2009): Managerial Recommendations for Service Innovations in Different Product-Service Systems. In Sakao, T., Lindahl, M., Editors. Introduction to Product/Service-System Design, Springer Verlag, London.

[11] Krishnan, V., Ulrich, K.T., (2001): Product Development Decisions: A Review of the Literature, Management Science, Vol. 47, No. 1, pp. 1-21.
[12] Ulrich, K.T., Eppinger, S.D., (2008): Product Design and Development, McGraw-Hill, Inc, Boston.

[13] Herrman, C., Kuntzky, K., Mennenga, M., Royer-Torney, M., Bergmann, L., (2009): Joint Framework for Product Service Systems and Life Cycle Management, in: Proceedings of the 2th CIRP International Conference on Industrial Product/Service Systems, pp. 453-459, Linköping, Sweden.

[14] MOKA Consortium, (2001): Managing Engineering Knowledge. MOKA: Methodology for Knowledge Based Engineering Applications. Edited by Melody Stokes. Professional Engineering Publishing Limited, London.

[15] Ackerman, M., Pipek, V., Wulf, V., Editors. (2003): Sharing Expertise, Beyond Knowledge Management, Massachusetts Institute of Technology, USA.

[16] Swan, J., Newell, S., Scarborough, H., Hislop, D., (1999): Knowledge management and innovation: networks and networking, Journal of Knowledge Management, Vol. 3, No. 4, pp. 262-275.

[17] Erickson, T., Kellogg, W.A., (2003): Knowledge Communities: Online Environments for Supporting Knowledge Management and Its Social Context. In Ackerman, M., Pipek, V., Wulf, V., Editors. Sharing Expertise, Beyond Knowledge Management, Massachusetts Institute of Technology, USA.

[18] Castells, M., (1996): The Information Age, Economy, society and culture, The rise of the network society, Blackwell Publishers, USA, Vol. 1, pp. 153-172.

[19] Tukker, A., Van den Berg, C., Tischner, U., (2006): Productservices: a specific value proposition. In Tukker, A., Tischner, U., Editors. New Business for Old Europe: Product-Service Development, Competitiveness and sustainability, Greenleaf Publishing, UK, pp. 22-34.

[20] Manzini, E., Vezzoli, C., (2001): Product-Service Systems and Sustainability: Opportunities for sustainable solutions, Report UNEP.

[21] Tukker, A., Tischner, U., (2006): Note from the field: Productservices as a research field: past, present and future. Reflections from a decade of research, Journal of Cleaner Production Vol. 14, No. 17, pp. 1552-1556.

[22] Rittel, H., Webber, M., (1973): Dilemmas in General Theory of Planning, Policy Sciences, Vol. 4, pp. 155-169.

[23] Hyman, B., (1998): Fundamentals of Engineering Design, Prentice Hall, Upper Saddle River, NJ.

[24] Randall, D., Harper, R., Rouncefield, M., (2007): Fieldwork for design - theory and practice, Springer-Verlag, London.

[25] Popadiuk, S., Choo, C.W., (2006): Innovation and Knowledge Creation: How are these concepts related?, International Journal of Information Management, Vol. 26 pp. 302-312.

[26] Nergård, H., (2009): Knowledge engineering models as experience carriers, Doctoral thesis, Division for Functional product development, Lulea University of Technology, Sweden.

[27] Mintzberg, H., Westley, F., (2001): Decision Making: It's not what you think, MIT Sloan Management Review, Spring, pp. 89-93.

[28] Modica S. and Rustichini A., (1994): Awareness and partitional information structures, Theory and Decision, Vol. 37, No. 1, pp. 107-124. 